\title{
Pooling, Tranching and Credit Expansion
}

\author{
By Spiros Bougheas
}

School of Economics, University of Nottingham, Nottingham NG7 2RD; and

CES-ifo; e-mail: spiros.bougheas@nottingham.ac.uk

\begin{abstract}
Traditionally banks have used securitization for expanding credit and thus their profitability. It has been well documented that, at least before the 2008 crisis, many banks were keeping a high proportion of the securities that they created on their own balance-sheets. Those securities retained included both the high-risk 'equity' tranche and the low-risk AAA-rated tranche. This paper builds a simple model of securitization that accounts for the above retention strategies. Banks in the model retained the equity tranche as skin in the game in order to mitigate moral hazard concerns while they post the low-risk tranche as collateral in order to take advantage of the yield curve. When variations in loan quality are introduced the predicted retention strategies match well those found in empirical studies.
\end{abstract}

JEL: G21, G24 


\section{Introduction}

As time goes on banks rely less on deposits for financing their activities and more on securitization and leverage (Greenbaum and Thakor, 1987; Mester, 1992). These options for raising funds have allowed them to substantially expand their balance sheets and thus their profitability albeit, as the crisis of 2008 has made clear, at higher levels of risk exposure (Brunnermeier, 2009; Dell'Ariccia et al., 2009; Mian and Sufi, 2009). Securitization itself has also been the subject of financial innovation. Some of the securities are straight passthroughs as, for example, in the case of some types of loan sales (Pennacchi, 1988; Carlstrom and Samolyk, 1995; Gorton and Pennacchi, 1995) while other securities are created by pooling and tranching the cash-flows of banking assets. ${ }^{1}$ In the latter case, a variety of new securities are formed differentiated by their default risk and then sold to investors according to their risk appetite.

The initial objective of securitization was to boost liquidity by enabling banks to sell their assets and use the funds raised from these sales to offer new loans. However, it has been well documented that, at least before the crisis, many banks were keeping a high proportion of the securities that they created on their own balance-sheets. What is more surprising is that those securities retained included both the high-risk 'equity' tranche (Acharya et al., 2009) and the low-risk AAA-rated tranche (Acharya and Schnabl, 2009). ${ }^{2}$ The same banks, especially those that are large and grow fast, have also increasingly relied on short-term wholesale financial markets for raising funds (Demirgüç-Kunt and Huizinga, 2010).

In this paper, I provide a theoretical account for the above observations by introducing into the Shleifer and Vishny (2010) banking model a monitoring role for banks, similar to that in Holmström and Tirole (1997). ${ }^{3}$ In Shleifer and Vishny (2010) the form of contracts related to the sale of securities to investors and the form of contracts agreed between the bank and its lenders are both exogenously given. In particular, investors require the bank to keep on its books as 'skin in the game' a fixed fraction of the securities that it creates while lenders impose a 'haircut' on bank lending that is defined as the ratio of the size of the loan in

\footnotetext{
${ }^{1}$ This method of security creation has attracted an extensive literature reviewed by Gorton and Metrick (2013) who also provide a detail description of the institutional (including the legal) environment within which this process takes place.

${ }^{2}$ Acharya and Schnabl (2009) report that if someone includes those AAA-rated asset backed securities that banks held off their balance-sheets in ABCP conduits and SIVs then the fraction retained rises above $50 \%$. See also Jaffee et al. (2009) and Krishnamurthy (2008).

${ }^{3}$ The purpose of contract design is to provide a solution to delegated monitoring, a problem previously analyzed by Diamond (1984), Ramakrishnan and Thakor (1984), Boyd and Prescott (1986) and Winton (2003). These papers are part of a very extensive literature that analyzes the role of banks as monitors; for a review see Bhattacharya and Thakor (1993).
} 
relation to the value of the securities that the bank posts as collateral. By applying results derived in the literature within the context of a borrower-lender relationship to a delegated monitoring setting, I am able to derive the optimal contractual forms that the bank agrees with its investors and lenders. In particular, I demonstrate that, when the returns on the loans are not perfectly correlated, pooling and tranching of the cash-flows generated by the loans that the bank offers to its clients is optimal. In the context of the present model, where all parties are risk-neutral, the benefits of pooling are not the result of risk diversification. By keeping a fraction of the equity tranche on its books, the bank assures investors that it still has an incentive to monitor its clients. I further show that, when I allow for projects of different quality the skin in the game declines as quality improves. What the bank does with the AAArated tranche depends on the relative cost of raising funds between selling these securities to investors and increasing its leverage by posting them as collateral. The model predicts that when the bank uses leverage to finance its activities it can reduce haircuts, and thus boost credit expansion, by posting as collateral securities that bear lower levels of risk.

The model rationalizes the practices that for a long time banks have been using to expand their activities. However, the global financial crisis has made painfully clear that many institutions around the world that have adopted those practices only survived the crisis because of very expensive government bailouts. There is a very fast growing literature devoted not only to identifying the causes of the crisis but also to the design of appropriate policy responses. ${ }^{4}$ Along with lax monetary conditions, regulatory failure, underestimation of systemic risk, poor performance by rating agencies, and a weak banking governance structure, there are aspects of financial innovation that have also been regarded responsible for the financial crisis. ${ }^{5}$ But as the Federal Reserve chairman Ben Bernanke has suggested it is important to distinguish financial innovation from its implementation. ${ }^{6}$ Financial innovation can lead to new products that offer efficient solutions to agency problems in financial markets. In the model below, securitization by pooling and tranching of asset returns in conjunction with certain retention strategies ensure investors that the bank has a

\footnotetext{
${ }^{4}$ See for example Acharya and Richardson (2009) and Dewatripont et al. (2010) and the two symposia in the Journal of Economic Perspectives (Winter 2009, Winter 2010).

${ }^{5}$ Gennaioli et al. (2012) have shown that when consumers neglect small probability risks financial innovation can indeed lead to higher financial market volatility.

6 The following quote is taken from his speech "Financial Innovation and Consumer Protection" that he delivered at the Federal Reserve System's Sixth Biennial Community Affairs Research Conference, Washington, D.C. in April, 2009: “...as we have seen only too clearly during the past two years, innovation that is inappropriately implemented can be positively harmful. In short, it would be unwise to try to stop financial innovation, but we must be more alert to its risks and the need to manage those risks properly."
} 
strong incentive to monitor its clients, thus, enabling it to expand its balance sheet and hence its profits.

I develop the model in Section 3 and in the next two sections I focus on the case when all loan returns are perfectly correlated. In Section 4, I analyze credit expansion for the case when the bank creates straight pass-through securities while in Section 5 I derive the optimal form of securitization contracts. I show that by using tranching the bank can create (a) highrisk securities which, if they are kept on its books, enhance its incentive to monitor its clients, (b) very low-risk securities that can be posted as collateral, and (c) medium-risk securities that are sold to investors. In Section 6, I extend the analysis to the case where loan returns are independently distributed and show that incentives can be further improved by pooling, in addition to tranching, loan payoffs. By combining pooling and tranching the bank conditions security payoffs on the proportion of projects that succeed. The bank by keeping on its books the high-risk tranche that pays out only when a sufficiently high fraction of projects succeed has even stronger incentives to monitor its clients. In section 7, I allow for project quality variations and address issues related to the financial crisis. I conclude in Section 8.

\section{Related Literature}

One old method for tranching payoffs is their separation into seniority claims. The advantages of this practice for mechanism design have been the subject of a very long literature and the work that is most closely related to the present one is Innes (1990). In his model the lender cannot observe the level of effort exerted by the entrepreneur. Given that expected profits increase with effort, Innes (1990) shows that, if (a) the entrepreneur has limited liability, and (b) the loan repayment is restricted to be non-decreasing in profits, it is optimal for the lender to offer a standard-debt contract. Thus, the entrepreneur holds the risky equity tranche that pays out in states that become more likely as she exerts higher levels of effort. Similarly, in this model the bank's incentives to monitor its clients are strongest when it holds the risky-equity tranche. Of course, the observation that financing loan sales using debt increases the bank's incentives to monitor is not new. ${ }^{7}$ One of the contributions of the present paper is to show that pooling and tranching can at least partially implement the optimal mechanism when bank asset returns are not perfectly correlated. ${ }^{8}$

What drives the results in Innes (1990) and in the present work is the assumption that the return distribution conditional on the level of effort (monitoring) satisfies the monotone

\footnotetext{
${ }^{7}$ See, for example, Pennacchi (1988), Gorton and Pennacchi (1995) and Parlour and Plantin (2008).

${ }^{8}$ Tirole (2006) has already shown that pooling and tranching of returns can improve incentives when the latter are not perfectly correlated but in this paper I further show the optimality of these arrangements.
} 
likelihood ratio property (MLRP). When this property is satisfied the observation of high returns leads to the inference that they were drawn from a distribution corresponding to high levels of effort. The benefits of pooling and tranching have also been demonstrated for environments where the property is violated. In Chiesa (2008) banks perform a monitoring role similar to the one in this paper. When monitoring is most valuable in those states where the systemic risk is high (economic downturns) she finds that it is optimal for the bank to sell its entire portfolio to investors and in addition offer them the option to sell it back to the bank at a pre-specified price. In Fender and Mitchell (2009) banks, rather than monitoring their clients after the signing of contracts, they screen them in advance in order to separate those with high-quality projects from the rest. ${ }^{9}$ They restrict their analysis to two types of securitization, namely, straight pass-through securities (what they call 'vertical slice') and securities created by pooling and tranching. They find that when MLPR is violated pooling and tranching is the best option along with a retention strategy where the bank keeps medium-risk securities (mezzanine tranche) on its books. The contribution of this paper is that it analyses securitization within a mechanism design framework, albeit for a simpler environment where MLPR is satisfied.

The present paper is also related to a strand of the literature that analyses securitization within a signalling framework. In DeMarzo and Duffie (1999) the bank has superior information about the quality of the loans that attempts to sell to investors and it uses the size of the 'skin in the game' as signal. In particular, the skin of the game increases with quality indicating that the bank is willing to hold on its books better quality assets. In contrast, in the present model the 'skin in the game' provides incentives for banks to monitor the projects that they finance. When projects of different quality are introduced the skin in the game declines as quality improves. The evidence, which I review in Section 7, is very thin but it suggests that the relationship might be negative. Weak support for the signalling framework it is not entirely surprising given that banks rely extensively on rating agencies for quality certification. Finally, DeMarzo (2005) demonstrates the advantages of pooling and tranching for the case when the seller of securities is informed. In his model, the advantages

\footnotetext{
${ }^{9}$ The two approaches are quite similar. Under the supposition that the bank needs to screen a fixed number of potential customers in order to identify one with a high-quality project the two models become isomorphic. The screening model is more suitable for the case when the bank securitizes mortgages while the monitoring model fits better the case of collaterarized loan obligations (CLOs) structured by pooling a variety of assets that, more recently, have included business loans.
} 
of pooling are due to the benefits of diversification. In this paper, I show that pooling can be optimal even in the absence of diversification concerns. ${ }^{10}$

\section{The Model}

There are four types of risk-neutral agents in the model: entrepreneurs who need funds to finance projects, banks which provide funds to entrepreneurs and then use the loans to create securities, investors who buy the securities and lenders who offer loans to the banks accepting as collateral securities that banks keep on their books. I would like to use the model to understand not only the contractual arrangements between the banks and the other agents but also the process of credit expansion allowed by these arrangements. Then, it will be convenient to analyze an environment where the period of credit expansion is relatively short in comparison to the duration period of projects. With that in mind, I consider a model with three dates: 0, 1 and T. All contracts are agreed during the period between dates 0 and 1 and all projects financed during this initial period mature at $\mathrm{T} .{ }^{11}$ The risk-free interest rate is equal to zero.

[Please insert Figure 1 about here]

\subsection{Projects}

All projects are identical and require an investment of one unit of the single good in the economy. Projects can either succeed in which case they yield pledgeable income $R_{H}$ or fail in which case they yield pledgeable income $R_{L}$, where $R_{H}>1>R_{L}$. The probability of success of a project depends on the behaviour of its owner (entrepreneur) who can either choose to exert effort or shirk. In the former case the probability of success is equal to $p_{h}$ while in the latter case the probability of success is equal to $p_{l}$, where $p_{h}>p_{l}$. ${ }^{12}$ The returns of all projects are perfectly correlated.

\subsection{Banks}

In modelling banks I follow closely Shleifer and Vishny (2010). The objective of banks is to maximize the value of final equity. Given that financial markets are competitive, bank's profit equals the revenues from the up-front fees that it collects when it finances new

\footnotetext{
${ }^{10}$ The advantages of tranching are also considered by Riddiough (1997). He considers the securitization of a single loan and therefore there is no pooling. In contrast, Glaeser and Kallal (1997) consider the advantages of pooling but allow for only pass-through securities.

${ }^{11}$ Between dates 0 and 1 transactions take place sequentially and therefore in a fully fledged general equilibrium model the pricing of securities would be affected by discounting. As long as this period is very short in relation to the duration of the contracts ignoring the effect of discounting on prices is inconsequential for our results.

${ }^{12}$ Clearly MLPR is satisfied given that project success is more likely when the entrepreneur exerts higher effort.
} 
projects. ${ }^{13}$ Thus, the above objective is equivalent to maximizing the number of projects that banks finance.

By monitoring a project at a cost $m$ a bank can ensure that its entrepreneur exerts effort. If a bank decides to finance a project it collects the up-front fee $f$ and an expected repayment of $1+m$ at date $\mathrm{T}$. The following condition ensures that a project will only be financed when its entrepreneur exerts effort:

$$
p_{l} R_{H}+\left(1-p_{l}\right) R_{L}<1<p_{h} R_{H}+\left(1-p_{h}\right) R_{L}-m \text {. }
$$

The first inequality states that if the bank does not monitor the project the expected value of the pledgeable income would be less than the size of the loan. The second inequality states that when the bank monitors there is enough pledgeable income to cover both the size of the loan and the monitoring cost. Banks offer entrepreneurs debt contracts. Let $V$ denote the repayment when the project succeeds. The loan repayment must satisfy the condition $\left(1-p_{h}\right) R_{l}+p_{h} V=1+m$ where the bank collects the whole payoff when the project fails. Solving for the repayment it yields

$$
V=\frac{1+m-\left(1-p_{h}\right) R_{l}}{p_{h}}
$$

\subsection{Credit Expansion without Securitization}

Let $E_{0}$ denote a bank's equity at date 0 . The bank will be able to fund $\frac{E_{0}}{1+m}$ projects and given that the only profits that the bank earns are due to the up-front fees it collects, the bank's expected final equity is given by $E_{T}=E_{0}\left(1+\frac{f}{1+m}\right)$.

\section{Fractional Securitization and Leverage}

In this section, I am going to expand the activities of banks by allowing them to securitize their loans. Through securitization banks will be able to expand credit, and thus profits, by selling a fraction of each security to the market. In addition, I will allow banks to post those securities that they keep on their books as collateral so that they can obtain loans

\footnotetext{
13 The underlying assumption, as in Shleifer and Vishny (2010, p.309), is that these fees are distributed to shareholders as dividends. The need for introducing these fees is because under perfectly competitive markets banks make zero profits and therefore should be indifferent between alternative securitization methods. By introducing fee revenues that are proportional to bank lending the preferred securitization method is the one that maximizes credit expansion. The fees can be rationalizes as follows. Under the assumption that each bank offers a slightly differentiated product, this would be, for example, because they have an expertise in a particular type of lending related either to a location or to a sector of the economy, then under monopolistic competition each bank's profits would be equal to a constant mark-up over its costs. In this model the fee reflects the mark-up.
} 
from the market. Before I examine securitization and leverage together, I will analyze each one separately.

\subsection{Fractional Securitization without Leverage}

Securitization involves the sale in the market of cash flow claims associated with loan repayments. The contact between the buyers and the bank must be designed so that the bank still has an incentive to monitor its clients. It is clear, that if a buyer were to buy an entire loan, that is its total payoffs in both states, the bank would not have an incentive to monitor the loan. But then (C1) implies that the price the buyer would be willing to pay for the loan is less than one, which is an offer that the bank would refuse given that it had lent one unit to the entrepreneur. This argument suggests that the bank must keep part of the payoffs of each loan on its books for a sale to take place. Let the bank keep a fraction $d$, known as 'skin in the game', of each loan on its books. Thus, the buyer has a claim on a fraction $1-d$ of the payoff for each loan that she buys a share. ${ }^{14}$ Competition among buyers ensures that the equilibrium price the buyer's share is equal to $(1-d)(1+m)$. Clearly, the lower the 'skin in the game' is the higher will be credit expansion and thus the higher the value of the bank's final equity.

Proposition 1: Suppose that the bank can expand its activities by using only fractional securitization. The optimal value of the skin in the game is given by

$$
d^{F}=\frac{m}{1-\rho+m}
$$

The bank's expected final equity under fractional securitization is given by

$$
E_{T}^{F}=E_{0}\left(1+\frac{f}{d^{F}} \frac{1}{1+m}\right) \text {. }
$$

Proof: If the bank monitors the loan then it will earn a net payoff equal to $f$. If the bank does not monitor the loan then it will earn a net payoff equal to $f+d\left[\left(1-p_{l}\right) R_{L}+p_{l} V\right]+$ $(1-d)(1+m)-1$. The second term is equal to the bank's payoff from the fraction of the loan that it kept on its books, the third term is equal to its revenues from the sale of the rest of the loan and the last term is equal to its initial investment. Comparing the two net payoffs shows that the bank will monitor the loan if the following incentive compatibility holds:

$$
d \geq \frac{m}{1-\rho+m}, \text { where } \rho \equiv\left(1-p_{l}\right) R_{L}+p_{l} V .
$$

\footnotetext{
${ }^{14}$ Without any loss of generality, I assume that the number of securities that the bank creates equals the number of projects it finances.
} 
$\rho$ is equal to the expected payoff of the loan given that bank does not monitor. The bank's incentive to monitor the project decreases with $\rho$ and the size of monitoring costs. Thus, the skin in the game is increasing in both of these variables. The incentive compatibility constraint defines all values for $d$ that offer incentives for the bank to monitor. Among those values the bank will choose the one that maximizes its expected final equity. A bank with equity $E_{0}$ at date 0 initially provides $\frac{E_{0}}{1+m}$ loans. From the first round of securitization receives revenues $(1-d) E_{0}$ and provides $\left(1-d^{F}\right) \frac{E_{0}}{1+m}$ additional loans. Repeating the process the bank by date 1 will provide in total $\frac{E_{0}}{1+m} \sum_{\tau=0}^{\infty}(1-d)^{\tau}=\frac{1}{d^{F}} \frac{E_{0}}{1+m}$ loans. Given that the bank's profits come from the fees it collects, these profits are proportional to the number of loans it provides and thus in equilibrium the incentive compatibility constraint will bind.

\subsection{Leverage without Securitization}

Banks can borrow funds from the market, and thus expand credit, by posting securities that they keep in their books as collateral. I assume that potential lenders offer to banks only secured loans. This, for example, will be the case if it is too costly for them to verify the bank's stochastic payoffs. In this section, I do not allow the bank to sell to the market any of the securities that it creates but keeps them on its books. Once more, I consider a bank that at date 0 has equity $E_{0}$.

Proposition 2: Suppose that the bank can expand its activities by using only leverage. The optimal value of the haircut is given by

$$
h=\frac{1+m-R_{L}}{1+m} .
$$

The bank's expected final equity under leverage is given by

$$
E_{T}^{L}=E_{0}\left(1+\frac{f}{h} \frac{1}{1+m}\right)
$$

Proof: The bank will initially finance, and thus securitize, $\frac{E_{0}}{1+m}$ loans. Given that (a) the returns of all loans are perfectly correlated, and (b) the bank raises funds in a competitive market, the collateral value of these initial loans, and thus the amount the bank can borrow, is equal to $\frac{E_{0}}{1+m} R_{L}$. With the new funds the bank can finance $\frac{E_{0}}{(1+m)^{2}} R_{L}$ additional loans which can also be used as collateral. The process repeats itself ad infinitum. The bank by date 1 will have in total created $\frac{E_{0}}{1+m} \sum_{\tau=0}^{\infty}\left(\frac{R_{L}}{1+m}\right)^{\tau}=\frac{E_{0}}{1+m-R_{L}}$ loans. The competitive market value of each 
security is equal to $1+m$. The collateral value of the same security is equal to $R_{L}$. The ratio

$h \equiv \frac{1+m-R_{L}}{1+m}$, that is the ratio of the difference between market value and collateral value to market value, is known as the 'haircut'.

Notice, that given that the loans are secured, lenders do not care about whether the bank monitors its clients. Having said that, as the bank keeps all the loans on its books and, moreover, only receives a payoff when the loans succeed, it has an even stronger incentive to monitor relative to the case when it does not lever its equity.

\subsection{Fractional Securitization with Leverage}

Now, I will allow the bank to engage in both fund raising activities. It can sell securities in the market and borrow funds by posting as collateral those securities it holds on its books. The bank is not allowed to sell any securities that it has already posted as collateral for a loan unless it does so to repay the loan. However, the bank is allowed to post as collateral securities that keeps in it books as skin in the game.

Proposition 3: Suppose that the bank can expand its activities by using both fractional securitization and leverage. The optimal value of the skin in the game is given by

$$
d^{F L} \equiv \frac{m}{\left(p_{h}-p_{l}\right) V}<d^{F}
$$

The bank's expected final equity is given by

$$
E_{T}^{F L}=E_{0}\left(1+\frac{f}{d^{F L} h} \frac{1}{1+m}\right)
$$

Proof: I begin by showing that the buyers of securities set the skin in the game lower when the bank posts the corresponding securities as collateral. The bank's net gain by not monitoring a loan is equal to $m-d\left(p_{h}-p_{l}\right) V$. Given that the bank is posting the security created from the loan as collateral it will earn a payoff only when the corresponding project succeeds. Then, the bank will monitor the loan if the following incentive compatibility constraint holds:

$$
d \geq \frac{m}{\left(p_{h}-p_{l}\right) V}
$$

Given that the bank's profits are increasing with credit expansion, the incentive compatibility constraint binds in equilibrium. To complete the proof of the first part of the Proposition, use (1) to substitute for $V$ in (6) and then subtract it from (2). 
Next, I examine the level of credit expansion when the bank uses both securitization and leverage to finance its activities. Recall that the bank cannot sell any securities that it has already posted as collateral and that a bank with equity $E_{0}$ at date 0 will initially finance $\frac{E_{0}}{1+m}$ projects and create the same number of securities. The bank will keep a fraction $d^{F L}$ of these securities as skin in the game and also post them as collateral in order to borrow from the market. Thus, the bank will be able to borrow $d^{F L} \frac{E_{0}}{1+m} R_{L}$ from lenders and receive (1$\left.d^{F L}\right) E_{0}$ from the sale of securities. The bank can now use the revenues from the sale of securities and the amount borrowed from the market to finance $\left(1-d^{F L}\right) \frac{E_{0}}{1+m}+$ $d^{F L} \frac{E_{0}}{(1+m)^{2}} R_{L}$ new projects. The bank will repeat the process by keeping a fraction $d^{F L}$ of the new loans as skin in the game and at the same time posting them as collateral to finance $2 d^{F L}\left(1-d^{F L}\right) \frac{E_{0}}{(1+m)^{2}} R_{L}+\left(1-d^{F L}\right)^{2} \frac{E_{0}}{1+m}+\left(d^{F L}\right)^{2} \frac{E_{0}}{(1+m)^{3}}\left(R_{L}\right)^{2}=\frac{E_{0}}{1+m}\left(\left(1-d^{F L}\right)+\right.$ $\left.d^{F L} \frac{1}{1+m} R_{L}\right)^{2}$ additional projects. By repeating the process ad infinitum the bank by date 1 will have created in total $\frac{E_{0}}{1+m} \sum_{\tau=0}^{\infty}\left(\left(1-d^{F L}\right)+d^{F L} \frac{1}{1+m} R_{L}\right)^{\tau}=\frac{1}{d^{F L}\left(1-\frac{R_{L}}{1+m}\right)}=\frac{1}{d^{F L} h}$ new loans.

Since the bank earns a payoff only when the project succeeds it has a stronger incentive to monitor and thus the buyers respond by asking for a lower skin in the game.

\section{Optimal Securitization Contracts}

Up to this point, I have assumed that when a bank sells securities it keeps a share $d$ of each security on its books and, thus, it receives a fraction $d$ of its payoffs in each state of the world. Now, I will demonstrate how a bank can further boost credit expansion, and thus increase its profits, by choosing an alternative way to split the payoffs of the projects.

\subsection{Optimal Securitization Contracts without Leverage}

For the moment, I will ignore leverage which I will reconsider in the following section. Suppose that the bank creates two securities out of each loan. The first security, which I denote $X_{B}$, will pay off $z_{H}$ if the project succeeds and $z_{L}$ if the project fails and the bank keeps it on its books. The second security, which I denote $X_{I}$, will pay off $V-z_{H}$ if the project succeeds and $R_{L}-z_{L}$ if the project fails and the bank sells it to investors. 
Fractional securitization imposes the additional constraint $\frac{z_{H}}{V}=\frac{z_{L}}{R_{L}}$. This means it allows only equity contracts. Now I relax this constraint. We can define as skin in the game the ratio of the bank's expected payoff from each loan to the total expected payoff of the loan, even if the payoffs to the two securities created from a loan are not proportional to their shares of equity in the loan.

Proposition 4: Suppose that project returns are perfectly correlated. The optimal value of the skin in the game under optimal securitization but without leverage is given by

$$
d^{S}=\frac{p_{h} m}{\left(p_{h}-p_{l}\right)(1+m)}
$$

The bank's expected final equity under optimal securitization but without leverage is given by

$$
E_{T}^{S}=E_{0}\left(1+\frac{f}{d^{S}} \frac{1}{1+m}\right)
$$

Proof: If the bank monitors the loan, its payoff will be equal to $p_{h} z_{H}+\left(1-p_{h}\right) z_{L}-m$ and if it does not monitor the loan its payoff will be equal to $p_{l} z_{H}+\left(1-p_{l}\right) z_{L}$. The bank's incentives to monitor increase with $z_{H}$ and decline with $z_{L}$. Then optimality requires:

$$
z_{L}=0 \text { and } z_{H}=\frac{m}{p_{h}-p_{l}} \text {. }
$$

Next, I consider credit expansion for a bank with equity at date 0 equal to $E_{0}$ that it has initially used to finance $\frac{E_{0}}{1+m}$ projects. The bank will create $\frac{E_{0}}{1+m}$ securities of type $X_{B}$ that will keep on its books and $\frac{E_{0}}{1+m}$ securities of type $X_{I}$ that will sell to investors (thus completely allocating the payoffs of the loans), raising revenues $P^{S} \frac{E_{0}}{1+m}$, where $P^{S}$ denotes the price of a type $X_{I}$ security. With these revenues the bank will be able to finance $P^{S} \frac{E_{0}}{(1+m)^{2}}$ additional loans and eventually $\frac{E_{0}}{1+m}\left(\frac{1}{1-\frac{P^{S}}{1+m}}\right)$ loans in total.

To complete the proof of the proposition I need to derive $P^{S}$ and $d^{S}$. From the solution for $z_{H}$ it follows that the bank's expected payoff from each security of type $X_{B}$ is equal to $\frac{p_{h} m}{\left(p_{h}-p_{l}\right)}$. $d^{S}$ is obtained by dividing the last expression by each loan's expected payoff, equal to $1+m$. Finally, the equilibrium price of a security of type $X_{I}$ is equal to the difference between these two payoffs that is

$$
P^{S}=1+m-\frac{p_{h} m}{\left(p_{h}-p_{l}\right)}
$$


To derive the final equity substitute (11) in the expression derived above for the total number of loans.

The following proposition compares fractional with optimal securitization.

Proposition 5: (a) $d^{F L} h>d^{S}$, and (b) $E_{T}^{S}-E_{T}^{F L}>0$.

Proof: (a) Substituting for $V$ in the expression for $d^{F L}$ given by (6) and multiplying by $h$ given by (4) yields $\left(\frac{p_{h} m}{\left(p_{h}-p_{l}\right)(1+m)-\left(1-p_{h}\right) R_{L}}\right)\left(\frac{1+m-R_{L}}{1+m}\right)$ which can be shown to be greater than $\frac{p_{h} m}{\left(p_{h}-p_{l}\right)(1+m)}=d^{S}$. Part (b) follows after comparing (7) and (9) and noticing that the difference between the two expressions depends only on the two skins in the game.

The split of payoffs under optimal securitization, by enhancing the bank's incentives to monitor, lowers the skin in the game and thus boosts credit expansion.

\subsection{Optimal Securitization with Leverage}

The split of payoffs examined in the previous section does not allow the bank to lever its equity. The $X_{B}$ security that the bank keeps on its books has a zero payoff when the project fails and, given that the returns of all projects are perfectly correlated, it has zero collateral value. However, there is an alternative way of splitting the payoffs that would allow the bank to borrow from the market.

The bank can do three things with the securities that it creates. It can sell them or keep them on its books and post them as collateral or keep them on its books without posting them as collateral. Furthermore, as the collateral value of any security is equal to its minimum payoff between the two states of the world it will be optimal for the bank to post as collateral securities that offer the same payoff in the two states. Therefore, there are potentially five types of securities that the bank might want to issue. ${ }^{15}$ However, as I demonstrated in the previous section, it is never optimal for the bank to issue securities that pay off only when the project fails and keep them on its books. This is because these types of securities reduce the bank's incentive to monitor and would only keep them on its books if it can post them as collateral. It follows that there are only four types of securities that we need to consider.

The first security, which I denote $Y_{C}$ the bank keeps it on its books to post it as collateral and pays off $\bar{v}$ in both states of the. The second security, which I denote $Y_{I}^{L}$, is sold to investors and pays off $R_{L}-\bar{v}$ only when the project fails The third security, which I denote $Y_{B}^{H}$, the bank keeps it on its books and pays off $v_{H}$ only when the project succeeds.

\footnotetext{
${ }^{15}$ I exclude the possibility of securities with lotteries as state-contingent payoffs.
} 
The fourth security, which I denote $Y_{I}^{H}$, is sold to investors and pays off $V-v_{H}-\bar{v}$ only when the project succeeds. The following proposition states the main result.

Proposition 6: Suppose that project returns are perfectly correlated. The bank's expected final equity under optimal securitization

$$
E_{T}^{S L}=E_{T}^{S}=E_{0}\left(1+\frac{f}{\frac{p_{h}^{m}}{\left(p_{h}-p_{l}\right)(1+m)}} \frac{1}{1+m}\right)=E_{0}\left(1+\frac{f}{d^{S}} \frac{1}{1+m}\right),
$$

is independent of its level of leverage.

Proof: If the bank monitors the loan, its payoff will be equal to $p_{h} v_{H}-m$ and if it does not monitor the loan its payoff will be equal to $p_{l} v_{H}$. Keep in mind that when the project succeeds the bank has to repay $\bar{v}$ to its lenders. The bank's incentive to monitor increases with $v_{H}$ but its ability to expand credit decreases with $v_{H}$ and increases with $\bar{v}$. Thus, optimality requires:

$$
\bar{v}=R_{L} \text { and } v_{H}=\frac{m}{p_{h}-p_{l}},
$$

The bank's credit expansion ability is given by

$$
C^{S}=R_{L}+p_{h}\left(V-\frac{m}{p_{h}-p_{l}}-R_{L}\right)=1+m-\frac{p_{h} m}{p_{h}-p_{l}} .
$$

The first term is equal to the amount borrowed by posting security $Y_{C}$ as collateral. The second term is equal to the price of security $Y_{I}^{H}$ and thus is equal to the revenues received by selling it to investors. ${ }^{16}$

Therefore, a bank with equity at date 0 equal to $E_{0}$ that it has used to finance $\frac{E_{0}}{1+m}$ projects will receive $\frac{E_{0}}{1+m}\left(1+m-\frac{p_{h} m}{p_{h}-p_{l}}\right)$ from lenders and investors. With these funds the bank will be able to finance $\frac{E_{0}}{1+m}\left(1-\frac{p_{h}}{1+m} \frac{m}{p_{h}-p_{l}}\right)$ additional projects. Repeating the process ad infinitum the bank will, by date 1 , have created in total $\frac{E_{0}}{1+m} \sum_{\tau=0}^{\infty}\left(1-\frac{p_{h}}{1+m} \frac{m}{p_{h}-p_{l}}\right)^{\tau}=\frac{E_{0}}{1+m} \frac{1}{\frac{p_{h} m}{\left(p_{h}-p_{l}\right)(1+m)}}$ loans.

Under the optimal securitization arrangement the bank does not derive any additional benefits by borrowing from the market. This result is the securitization version of the ModiglianiMiller theorem. The bank can either sell the safe securities or post them as collateral. Given that, in the model, the required rate of return of investors and lenders is identical the bank is

\footnotetext{
${ }^{16}$ Security $Y_{B}^{H}$ does not show up as the bank keeps it on its books.
} 
indifferent as to how it finances its activities. In practice, banks have been financing a great deal of activity by borrowing.

\section{Independently Distributed Project Returns, Pooling and Tranching}

Up to this point, I have focused on the case where all project returns are perfectly correlated. In this section, I relax this assumption. The distribution of returns of each project is exactly the same as before. However, these returns are now independently distributed. To keep things simple, I assume that there are two types of projects, namely type $I$ and type $I I$ and four states of the world and that half of the projects in the bank's portfolio are type $I$ while the other half of the projects are type $I I$. The returns to projects of the same type are perfectly correlated. I assume that project types are observable and thus I eliminate any adverse selection considerations from the security design problem. The following table shows the distribution of returns: ${ }^{17}$

\section{[Please insert Table 1 about here]}

Given that the returns of projects of the same type are perfectly correlated, without any loss of generality, I assume that if the bank monitors a project it also monitors all other projects of the same type. Then, I consider the securitization of a portfolio created from two projects, one of each type. I also consider the case where the bank is able to post as collateral the securities that it keeps on its books.

I will divide the analysis of rest of this section into two parts. I will begin by considering the case of optimal securitization without pooling and tranching. Then, I will introduce these possibilities and by comparing the two cases make the benefits of pooling and tranching clear.

\subsection{Securitization without Pooling and Tranching}

Following the analysis in the last section, the bank can potentially issue the following types of securities. Security $Y_{C}(i)$, where $i=I, I I$, will pay off $\bar{v}(i)$ in all states of the world and the bank will keep it on its books and post it as collateral. Security $Y_{I}^{L}(i)$ will be sold to investors and pays off $R_{L}-\bar{v}(i)$ only when the project fails. Security $Y_{B}^{H}(i)$ is kept on the bank's books and pays off $v_{H}(i)$ only when the project succeeds. Security $Y_{I}^{H}(i)$ is sold to investors and pays off $V-v_{H}(i)-\bar{v}(i)$ only when the project succeeds.

\footnotetext{
${ }^{17}$ Notice that states $I$ and $I I$ are distinct equally probable states.
} 
After the bank signs an agreement with the investors it has three choices. It can monitor both projects or it can monitor only one project or it will not monitor either of the two projects. If the bank monitors both loans its payoff will be equal to $\left(\left(p_{h}\right)^{2}+\right.$ $\left.p_{h}\left(1-p_{h}\right)\right)\left(v_{H}(I)+v_{H}(I I)\right)-2 m$, keeping in mind that the bank receives a payoff only when a project succeeds. If the bank monitors only the type $I$ project its payoff will be equal to $\left(p_{h} p_{l}\right)\left(v_{H}(I)+v_{H}(I I)\right)+p_{h}\left(1-p_{l}\right) v_{H}(I)+p_{l}\left(1-p_{h}\right) v_{H}(I I)-m$ and if the bank monitors only the type $I I$ project its payoff will be equal to $\left(p_{h} p_{l}\right)\left(v_{H}(I)+v_{H}(I I)\right)+$ $p_{h}\left(1-p_{l}\right) v_{H}(I I)+p_{l}\left(1-p_{h}\right) v_{H}(I)-m$. Lastly, if the bank does not monitor any project its payoff will be equal to $\left(\left(p_{l}\right)^{2}+p_{l}\left(1-p_{l}\right)\right)\left(v_{H}(I)+v_{H}(I I)\right)$.

Given that $\bar{v}(I)$ and $\bar{v}(I I)$ do not appear in the above payoffs it is optimal to set them equal to $R_{L}$ so that credit expansion is maximized. It is also optimal to set $v_{H}(I)=v_{H}(I I)=$ $\hat{v}_{H}$. To see this suppose that $v_{H}(I)>v_{H}(I I)$. In this case the bank's payoff is greater when it only monitors the type $I$ project than when it only monitors the type $I I$ project. Then it is only the former payoff that matters for incentives. By decreasing $v_{H}(I)$ by $\delta$ and increasing $v_{H}(I I)$ by $\delta \frac{p_{h}\left(1-p_{l}\right)}{p_{l}\left(1-p_{h}\right)}$ that payoff remains the same but the corresponding incentive compatibility constraint would be relaxed. A similar argument eliminates $v_{H}(I)<v_{H}(I I)$. The discussion above implies that the optimal arrangement must satisfy the following incentive compatibility constraints:

$$
\left(\left(p_{h}\right)^{2}+p_{h}\left(1-p_{h}\right)\right) 2 \hat{v}_{H} \geq\left(p_{h} p_{l}\right) 2 \hat{v}_{H}+\left(p_{h}\left(1-p_{l}\right)+p_{l}\left(1-p_{h}\right)\right) \hat{v}_{H}+m
$$

and

$$
\left(\left(p_{h}\right)^{2}+p_{h}\left(1-p_{h}\right)\right) 2 \hat{v}_{H} \geq\left(\left(p_{l}\right)^{2}+p_{l}\left(1-p_{l}\right)\right) 2 \hat{v}_{H}+2 m
$$

It is straightforward to show that each of the two constraints implies that $\hat{v}_{H} \geq \frac{m}{p_{h}-p_{l}}$. The two constraints are identical as both the benefits and the costs are doubled when the bank decides not to monitor at all rather than monitoring only one of the projects.

The solution derived above is the same as the one obtained for the case of perfect correlation. This is because the incentives for monitoring are designed at the project level and therefore the degree of correlation of project returns does not affect the design.

\subsection{Securitization with Pooling and Tranching}

In this section, I show how the bank can further boost credit expansion through the creation of new types of securities designed by pooling and tranching the payoffs of the loans 
on its balance sheet. Although these additional benefits are only possible when the project returns are not perfectly correlated they are not the result of diversification as all agents are risk neutral. The analysis in this section proceeds in two steps. I will begin by characterizing the optimal pooling and tranching arrangement, that is among all possible pooling and tranching contracts I will choose the one that maximizes the bank's final equity (credit expansion). Then I will demonstrate the optimality of pooling and tranching. In other words, I will demonstrate that any securitization contract that maximizes the bank's final equity must involve pooling and tranching.

The bank will issue four types of securities. The following table shows their statecontingent payoffs.

[Please insert Table 2 about here]

Security $W_{C}^{0}$ is riskless having a payoff equal to $2 R_{L}$ in every state of the world. Therefore, this security is created by pooling together the two $Y_{C}(i)$ securities discussed in the previous section. This security is either posted as collateral or is sold to investors. $W_{I}^{L}$ is a low-risk security that has a payoff equal to zero in state $L$ and a payoff equal to $V-R_{L}$ in all other states. The security is created by pooling the payoffs of the two loans in states $I$ and $I I$ and half the payoff of the two loans in state $H$ after subtracting first the payoff of security $W_{C}^{0}$. This security is sold to investors. The other two securities are high-risk and they only offer a positive payoff in state $H$. Security $W_{I}^{H}$ is sold to investors and has a payoff equal to $V-$ $w_{H}-R_{L}$ while security $W_{B}^{H}$ has a payoff equal to $w_{H}$ and the bank keeps it on its books. Thus, there are three 'tranches': a riskless 'tranche' (security $W_{C}^{0}$ ), a low-risk tranche (security $W_{I}^{L}$ ) and a high-risk tranche (securities $W_{I}^{H}$ and $W_{B}^{H}$ ).

Proposition 7: Suppose that project returns are independently distributed. The bank's expected final equity under pooling and tranching is given by:

$$
E_{T}^{P T}=E_{0}\left(1+\frac{f}{\frac{\left(p_{h}\right)^{2} m}{\left.\left(p_{h}\right)^{2}-\left(p_{l}\right)^{2}\right)(1+m)}} \frac{1}{1+m}\right)=E_{0}\left(1+\frac{f}{d^{P T}} \frac{1}{1+m}\right) .
$$

Proof: If the bank monitors the two loans its net payoff will be equal to $\left(p_{h}\right)^{2} w_{H}-2 m$ and if it does not monitor the two loans its net payoff will be equal to $\left(p_{l}\right)^{2} w_{H}$. Given that the bank's credit expansion ability is decreasing with $w_{H}$, optimality requires that:

$$
w_{H}=\frac{2 m}{\left(p_{h}\right)^{2}-\left(p_{l}\right)^{2}} .
$$


It is crucial that the payoff of security $W_{I}^{L}$ in state $H$ is created by pooling and halving the payoffs of the two loans in that state. The same payoff can be created by separating the payoffs of the two loans but in that case the bank would not have an incentive to monitor the loan that is not on its books. To complete the argument, I need to show that with pooling the bank does not have an incentive to monitor only one loan. A sufficient condition to prevent this is to have $w_{H} \geq \frac{m}{\left(p_{h}\right)^{2}-p_{h} p_{l}}$. However, $w_{H}=\frac{2 m}{\left(p_{h}\right)^{2}-\left(p_{l}\right)^{2}}=\frac{2 m}{\left(p_{h}-p_{l}\right)\left(p_{h}+p_{l}\right)}>\frac{m}{p_{h}\left(p_{h-} p_{l}\right)}=$ $\frac{m}{\left(p_{h}\right)^{2}-p_{h} p_{l}}$ and, thus, the constraint does not bind.

The bank's per loan credit expansion ability under pooling and tranching is given by:

$$
C^{P T}=\frac{2 R_{L}+\left(1-\left(1-p_{h}\right)^{2}\right)\left(V-R_{L}\right)+\left(p_{h}\right)^{2}\left(V-\widehat{w}_{H}-R_{L}\right)}{2}=(1+m)-\frac{\left(p_{h}\right)^{2} m}{\left(p_{h}\right)^{2}-\left(p_{l}\right)^{2}} .
$$

The three terms on the numerator after the first equality are equal to the bank's revenues from the sale of securities $W_{C}^{0}, W_{I}^{L}$ and $W_{I}^{H}$, respectively, created from the pooling of the payoffs of two loans. The proof is completed by following the same steps as for the case when project returns are perfectly correlated.

In the statement of the proposition $d^{P T}$ captures the skin in the game under the new arrangement which I can use to identify the benefits of pooling and tranching as reflected in the ability of the bank to further increase credit expansion.

Proposition 8: $(a) d^{S}>d^{P T}$, and $(b) E_{T}^{P T}-E_{T}^{S}>0$.

Proof: (a) $\frac{\left(p_{h}\right)^{2}}{\left(\left(p_{h}\right)^{2}-\left(p_{l}\right)^{2}\right)}=\left(\frac{p_{h}}{p_{h}-p_{l}}\right)\left(\frac{p_{h}}{p_{h}+p_{l}}\right)>\left(\frac{p_{h}}{p_{h}-p_{l}}\right)$. (b) It follows after comparing (12) and (15).

The intuition for the above result is that pooling and tranching concentrate the bank's payoffs on those states where the incentives for monitoring are the strongest. The securitization arrangement that is optimal when project returns are perfectly correlated is not optimal when the same returns are imperfectly correlated as it offers a payoff to the bank on those states where only one project is successful. Under the new arrangement the bank receives a payoff only in state $H$ (when both projects succeed).

Up to this point, I have demonstrated that when projects returns are not perfectly correlated pooling and tranching strictly dominates any arrangement that does not pool projects payoffs together. Next, I derive the sharing rule for loan payoffs that maximizes the bank's final equity and then show under what conditions it can be implemented by pooling and tranching. 


\subsection{Optimality of Pooling and Tranching}

Without any loss of generality, I shall ignore leverage and, thus, assume that the bank shares the loan payoffs only with investors. Let $u_{j}^{i}$, where $i=I, I I$ and $j=H, I, I I, L$, be nonnegative real numbers denoting the bank's payoff form the loan repayment of project $i$ in state $j$. These payoffs must satisfy the following constraints:

$$
u_{L}^{I} \leq R_{L}, u_{L}^{I I} \leq R_{L}, u_{I I}^{I} \leq R_{L}, u_{I}^{I I} \leq R_{L}, u_{I}^{I} \leq V, u_{I I}^{I I} \leq V, u_{H}^{I} \leq V, u_{H}^{I I} \leq V
$$

The objective is to choose $u_{j}^{i}$ to maximize the bank's profits (which are proportional to credit expansion) subject to the participation constraint of investors, the set of inequalities (18) and the incentive compatibility constraints that ensure that the bank has an incentive to monitor the projects. Given that investors make zero profits in equilibrium and credit expansion is inversely related to the bank's share of loan payoffs, the above objective is equivalent to choosing $u_{j}^{i}$ to minimize the bank's expected payoff subject to (18) and the incentive compatibility constraints:

$$
\begin{aligned}
& \operatorname{Min}\left\{\left(p_{h}\right)^{2}\left(u_{H}^{I}+u_{H}^{I I}\right)+p_{h}\left(1-p_{h}\right)\left(u_{I}^{I}+u_{I I}^{I}+u_{I}^{I I}+u_{I I}^{I I}\right)+\left(1-p_{h}\right)^{2}\left(u_{L}^{I}+u_{L}^{I I}\right)\right\} \\
& \text { subject to: } \\
& \left(p_{h}\right)^{2}\left(u_{H}^{I}+u_{H}^{I I}\right)+p_{h}\left(1-p_{h}\right)\left(u_{I}^{I}+u_{I I}^{I}+u_{I}^{I I}+u_{I I}^{I I}\right)+\left(1-p_{h}\right)^{2}\left(u_{L}^{I}+u_{L}^{I I}\right)-m \geq \\
& p_{h} p_{l}\left(u_{H}^{I}+u_{H}^{I I}\right)+p_{h}\left(1-p_{l}\right)\left(u_{I}^{I}+u_{I I}^{I}+u_{I}^{I I}+u_{I I}^{I I}\right)+\left(1-p_{h}\right)\left(1-p_{l}\right)\left(u_{L}^{I}+u_{L}^{I I}\right)
\end{aligned}
$$

and

$$
\begin{gathered}
\left(p_{h}\right)^{2}\left(u_{H}^{I}+u_{H}^{I I}\right)+p_{h}\left(1-p_{h}\right)\left(u_{I}^{I}+u_{I I}^{I}+u_{I}^{I I}+u_{I I}^{I I}\right)+\left(1-p_{h}\right)^{2}\left(u_{L}^{I}+u_{L}^{I I}\right)-2 m \\
\geq \\
\left(p_{l}\right)^{2}\left(u_{H}^{I}+u_{H}^{I I}\right)+p_{l}\left(1-p_{l}\right)\left(u_{I}^{I}+u_{I I}^{I}+u_{I}^{I I}+u_{I I}^{I I}\right)+\left(1-p_{l}\right)^{2}\left(u_{L}^{I}+u_{L}^{I I}\right)
\end{gathered}
$$

Constraint (19) ensures that the bank does not have an incentive to monitor only one project. Although, in principle, there are two such constraints, symmetry implies that they are identical. Constraint (20) ensures that the bank does not have an incentive not to monitor at all. Linearity implies that if (20) is satisfied so is (19). Symmetry also implies that $u_{H}^{I}=$ $u_{H}^{I I}=u_{H}, u_{I}^{I}=u_{I}^{I I}=u_{I}, u_{I I}^{I}=u_{I I}^{I I}=u_{I I}$ and $u_{L}^{I}=u_{L}^{I I}=u_{L}$. Furthermore the inequality $p_{h}>p_{l}$ implies that it is optimal to set $u_{L}=0$. The above arguments imply that the optimization problem can be simplified to:

$$
\operatorname{Min}\left\{\left(p_{h}\right)^{2} 2 u_{H}+p_{h}\left(1-p_{h}\right)\left(u_{I}+u_{I I}\right)\right\}
$$

subject to: 


$$
\left(p_{h}\right)^{2} 2 u_{H}+p_{h}\left(1-p_{h}\right)\left(u_{I}+u_{I I}\right)-2 m \geq\left(p_{l}\right)^{2} 2 u_{H}+p_{l}\left(1-p_{l}\right)\left(u_{I}+u_{I I}\right)
$$

Given that $\left(p_{h}\right)^{2}-\left(p_{l}\right)^{2}>p_{h}\left(1-p_{h}\right)-p_{l}\left(1-p_{l}\right)$, if at the optimum $u_{H}<V$ then $u_{I}=u_{I I}=0$. Then, the following proposition describes the optimum sharing arrangement between the bank and its investors:

\section{Proposition 9:}

i) If $\frac{m}{\left(p_{h}\right)^{2}-\left(p_{l}\right)^{2}} \leq V$ then $u_{H}=\frac{m}{\left(p_{h}\right)^{2}-\left(p_{l}\right)^{2}}$ and $u_{I}+u_{I I}=0$, and

ii) if $\frac{m}{\left(p_{h}\right)^{2}-\left(p_{l}\right)^{2}}>V$ then $u_{H}=V$ and $u_{I}+u_{I I}=\frac{2\left(\left(\left(p_{h}\right)^{2}-\left(p_{l}\right)^{2}\right) V-m\right)}{p_{l}\left(1-p_{l}\right)-p_{h}\left(1-p_{h}\right)}$

In order for preserve the bank's incentives to monitor, the optimal contract requires the bank to keep some securities on its books. However, doing so reduces its ability to expand credit and therefore optimality also requires that the skin in the game is minimized. This is achieved, if feasible, by restricting the bank to receiving a payoff only in the high-risk state.

\section{Proposition 10:}

If $\frac{2 m}{\left(p_{h}\right)^{2}-\left(p_{l}\right)^{2}} \leq V-R_{L}$ then the optimum can be implemented by pooling and tranching where $w_{H}=\frac{2 m}{\left(p_{h}\right)^{2}-\left(p_{l}\right)^{2}}$.

The proposition follows directly from Table 1 . Notice that $w_{H}=2 u_{H}$. This is because $u_{H}$ is equal to the optimal bank payoff from each loan in state $H$ but under pooling and tranching the bank receives a payoff form only one of the loans and therefore it needs to be doubled to yield the same expected payoff.

The reason that the condition is not necessary is because even when the inequality is not satisfied, it might be still possible to partially implement the optimal solution by pooling and tranching. In order to increase the bank's payoff in state $H$ so as to ensure it will monitor its loan portfolio the payoff of the safe security must be reduced. But for the latter to remain riskless, its payoffs in all states must be reduced by the same amount. Now additional securities will be created by the residual payoffs in all remaining states.

According to the pooling and tranching arrangement analyzed in this part of the paper, the bank keeps on its books the low risk tranche (security $W_{C}^{0}$ ) that posts as collateral and a portion of the high-risk trance (security $W_{B}^{H}$ ) as skin in the game. These retention strategies are consistent with the practices that banks followed prior to the 2008 crisis (Acharya et al., 2009; Acharya and Schnabl, 2009). 


\section{Signalling versus Monitoring: Project Quality and the Skin in the Game}

There is quite a lot of empirical work on securitization related to moral hazard and adverse selection issues and the evidence is mixed. The empirical works by Berndt and Gupta (2009) and Elul (2009) suggest that securitization has a detrimental effect on loan quality but it cannot discriminate between the causes, namely, between moral hazard and adverse selection. The studies by An et al. (2009) and Downing et al. (2009) provide empirical support for the adverse selection interpretation. In contrast, Keys et al. (2009) present evidence that is consistent with the presence of moral hazard in the subprime loan market (lack of screening and monitoring) but not with "strategic adverse selection". That term refers to the ability of banks to select the quality of the loans they offer for sale to investors. This is in addition to those arising from asymmetric information. Most of this work uses data from mortgagebacked securities. Benmelech et al. (2010) analyzing collateralized loan obligations find that syndication significantly reduces adverse selection concerns.

Another way of testing the monitoring and the signalling models is to use their predictions about the relationship between loan quality and the skin in the game. Up to this point, I have assumed that the return distribution of all projects is identical. Now, I relax this assumption in order to consider how the quality of the project affects the skin in the game, that is, the portion of the corresponding loan that the bank keeps on its books. To keep the analysis simple, I consider the case of perfect correlation of returns so that there is no pooling. From (12) the skin in the game is given by:

$$
d^{S}=\frac{p_{h} m}{\left(p_{h}-p_{l}\right)(1+m)} \text {. }
$$

Better project quality can be captured by either a higher $p_{h}$ or a lower $p_{l}$. In Tirole's (2006) interpretation either of these changes leads to a reduction in agency costs; put differently, there are stronger incentives to monitor better quality projects. Clearly, (16) implies that the skin in the game should increase as project quality deteriorates.

In contrast, DeMarzo and Duffie (1999) find that when the bank has superior information about project quality the skin in the game rises as project quality improves. In their model the bank, by showing a willingness to keep a higher fraction of the securities on its books, signals that the underlying assets are of better quality.

There are a couple of papers that look directly at the relationship between loan quality and the skin and the game (Chen et al. 2008; Demiroglu and James, 2012). Both find that the skin in the game decreases as quality improves a finding consistent with the present model. 


\section{Conclusions}

The goal of this paper is to provide a simple model that captures the practices that modern banks employ to expand credit and thus profitability. It is well understood now that many banks that adopted such practices have been principal players in the recent financial turmoil. But one point that this paper emphasizes is that financial innovation is not necessarily responsible for the crisis. By pooling and tranching the payoffs of various types of loans banks have created securities of different risk classes and expanded their activities either by selling these securities to investors or using them as collateral. With a simple model, I have shown how the banks can mitigate moral hazard by using pooling and tranching and that this leads to a decline in the skin in the game and thus credit expansion. I have also shown that the same process creates low-risk securities that lenders are willing to accept as collateral.

In addition to creating incentives for banks to either screen or monitor their clients, securitization also generates asymmetries in information about loan quality between banks on one hand and lenders and investors on the other. To keep things simple in my model the lowrisk tranche is riskless. The model can be easily extended to allow for some risk. As long as the risk level is below the maximum risk that lenders are willing to take, then banks can still post the low-risk securities as collateral. Within this extended version, where default becomes possible, it would be straightforward to show that, as the quality of the collateral deteriorates, lenders would require a larger haircut. One additional complication of risky debt is that both the pricing of debt and the level of the 'haircut' will be affected if lenders are risk averse. ${ }^{18}$

In the model developed in this paper, as in Shleifer and Vishny (2010), banks do not rely on deposits to finance their activities and, therefore, there is not any role for government policy that targets the welfare of depositors. There is no doubt that an increase in the complexity of financial products can exacerbate problems related to asymmetric information. But it is important to separate those aspects of financial innovation that aim to mitigate agency problems in financial markets from those that do not.

Acknowledgements: I would like to thank Neelam Jain, Daniel Seidmann, Tim Worrall, seminar participants at City University, the Editor James Forder and two anonymous referees for helpful comments and suggestions. The usual disclaimer applies.

18 See Geanakoplos and Zame (2009) for a general equilibrium treatment of collateral and default when investors are risk-averse. Simsek (2013) demonstrates that by allowing for disagreements related to the value of the collateral, the model can account for both the emergence of new complex contracts and the behaviour of asset prices before the recent crisis. 


\section{References}

Acharya, V., Philippon, T., Richardson, M., Roubini, N., 2009. The financial crisis of 20072009: Causes and remedies. In Acharya, V., Richardson, M. (Eds.) Restoring Financial Stability: How to Repair a Failed System, Wiley, New Brunswick, NJ.

Acharya, V., Richardson, M. (Eds.), 2009. Restoring Financial Stability: How to Repair a Failed System, Wiley, New Brunswick, NJ.

Acharya, V., Schnabl, P., 2009. How banks played the leverage game. In Acharya, V., Richardson, M. (Eds.) Restoring Financial Stability: How to Repair a Failed System, Wiley, New Brunswick, NJ.

An, X., Deng, Y., Gabriel, S., 2009. Value creation through securitization: evidence from the CMBS market. Journal of Real Estate Finance and Economics 38, 302-326.

Benmelech, E., Dlugosz, J., Ivashina, V., 2010. Securitization without adverse selection: the case of CLOs. NBER working paper No. 16766, Cambridge, MA.

Berndt, A., Gupta, A., 2009. Moral hazard and adverse selection in the originate-to-distribute model of bank credit. Journal of Monetary Economics. 56, 725-743.

Bhattacharya, S., Thakor, A., 1993. Contemporary banking theory. Journal of Financial Intermediation 3, 2-50.

Boyd, J., and Prescott, E., 1986. Financial intermediary coalitions. Journal of Economic Theory 38, 211-232.

Brunnermeier, M., 2009. Deciphering the liquidity and credit crunch of 2007-2008. Journal of Economic Perspectives 23, 77-100.

Carlstrom, C., Samolyk, K., 1995. Loan sales as a response to market-based capital constraints. Journal of Banking and Finance 19, 627-646.

Chen, W., Liu, C., Ryan, S., 2008. Characteristics of securitization that determine issuers' retention of the risks of securitized assets. The Accounting Review 83, 1181-1215.

Chiesa, G., 2008. Optimal credit transfer, monitored finance, and banks. Journal of Financial Intermediation 17, 464-477.

Dell'Ariccia, G., Ingan, D., Laeven, L., 2009. Credit booms and lending standards: evidence from the subprime mortgage market. CentER working paper No. 2009-46S, Tilburg University.

DeMarzo, P., 2005. The pooling and tranching of securities: a model of informed Intermediation. Review of Financial Studies 18, 1-35.

DeMarzo, P., and Duffie, D., 1999. A liquidity-based model of security design. Econometrica 
67, 65-99.

Demirgüç-Kunt, A., Huizinga, H., 2010. Bank activity and funding strategies: the impact on risk and returns. Journal of Financial Economics 98, 626-650.

Demiroglu, C., James, C., 2012. How important is having skin in the game? Originatorsponsor affiliation and losses on mortgage-backed securities. Review of Financial Studies 25, 3217-3258.

Dewatripont, M., Rochet, J.-C., Tirole, J., 2010. Balancing the Banks: Global Lessons from the Financial Crisis, Princeton University Press, Princeton, NJ.

Diamond, D., 1984. Financial intermediation and delegated monitoring. Review of Economic Studies 51, 393-414.

Downing, C., Jaffee, D., Wallace, N., 2009. Is the market from mortgage-backed securities a market for lemons? Review of Financial Studies 22, 2457-2494.

Elul, R., 2009. Securitization and mortgage default. Federal Reserve Bank of Philadelphia working paper No. 09-21/R.

Fender, I., Mitchell, J., 2009. Incentives and tranche retention in securitization: a screening model. BIS working paper No. 289, Bank of International Settlements, Basel.

Geanakoplos, J., Zame,W., 2009. Collateralized security markets. Unpublished Manuscript. http://pubmail.dklevine.com/archive/refs4661465000000000040.pdf (last accessed on $12 / 6 / 13)$.

Gennaioli, N., Shleifer, A., Vishny, R., 2012. Neglected risks, financial innovation, and financial fragility. Journal of Financial Economics 104, 452-468.

Glaeser, E., Kallal, H., 1997. Thin markets, asymmetric information, and mortgage-backed securities. Journal of Financial Intermediation 6, 64-86.

Gorton, G., Metrick, A., 2013. Securitization. In Constantinides, G., Harris, M., Stulz, R. (Eds.) Handbook of the Economics of Finance, North-Holland, Amsterdam.

Gorton, G., Pennacchi, G., 1995. Bank and loan sales: marketing nonmarketable assets. Journal of Monetary Economics 35, 389-411.

Greenbaum, S., Thakor, A., 1987. Bank funding modes: Securitization versus deposits. Journal of Banking and Finance 11, 379-401.

Holmström, B., Tirole, J., 1997. Financial intermediation, loanable funds, and the real sector. Quarterly journal of Economics 112, 663-692.

Jaffee, D., Lynch, A., Richardson, M., Van Nieuwerburgh., 2009. Mortgage origination and securitization in the financial crisis. In Acharya, V., Richardson, M. (Eds.) Restoring Financial Stability: How to Repair a Failed System, Wiley, New Brunswick, NJ. 
Innes, R., 1990. Limited liability and incentive contracting with ex-ante choices. Journal of Economic Theory 52, 45-67.

Krishnamurthy, A., 2008. The financial meltdown: data and diagnoses. Unpublished Manuscript.

http://www.kellogg.northwestern.edu/ /media/Files/Faculty/Research/Diagnosis.ashx (last accessed on 12/6/13).

Keys, B., Mukherjee, T., Seru, A., Vig, V., 2009. Financial regulation and securitization: evidence from subprime loans. Journal of Monetary Economics 56, 700-720.

Mester, L., 1992. Traditional and nontraditional banking: an information-theoretic approach. Journal of Banking and Finance 16, 545-566.

Mian, A., Sufi, A., 2009. The consequences of mortgage credit expansion: evidence from the 2007 mortgage default crisis. Quarterly Journal of Economics 124, 1449-1496..

Parlour, C., Plantin, G., 2008. Loan sales and relationship banking. Journal of Finance 63, 1291-1314.

Pennacchi, G., 1988. Loan sales and the cost of bank capital. Journal of Finance 43, 375-395.

Ramakrishnan, R., Thakor, A., 1984. Information reliability and a theory of financial intermediation. Review of Economic Studies 51, 415-432.

Riddiough, T., 1997. Optimal design of asset-backed securities. Journal of Financial Intermediation 6, 121-152.

Shleifer, A., Vishny, R., 2010. Unstable banking. Journal of Financial Economics 97, 306318.

Simsek, A., 2013. Belief disagreements and collateral constraints. Econometrica 81, 1-53.

Tirole, J., 2006. The Theory of Corporate Finance, Princeton University Press, Princeton, NJ.

Winton, A., 2003. International liquidity needs and the structure of monitored finance.

Review of Financial Studies 16, 1273-1313. 
Figure 1: Time Line of the Model

\section{Time Line}

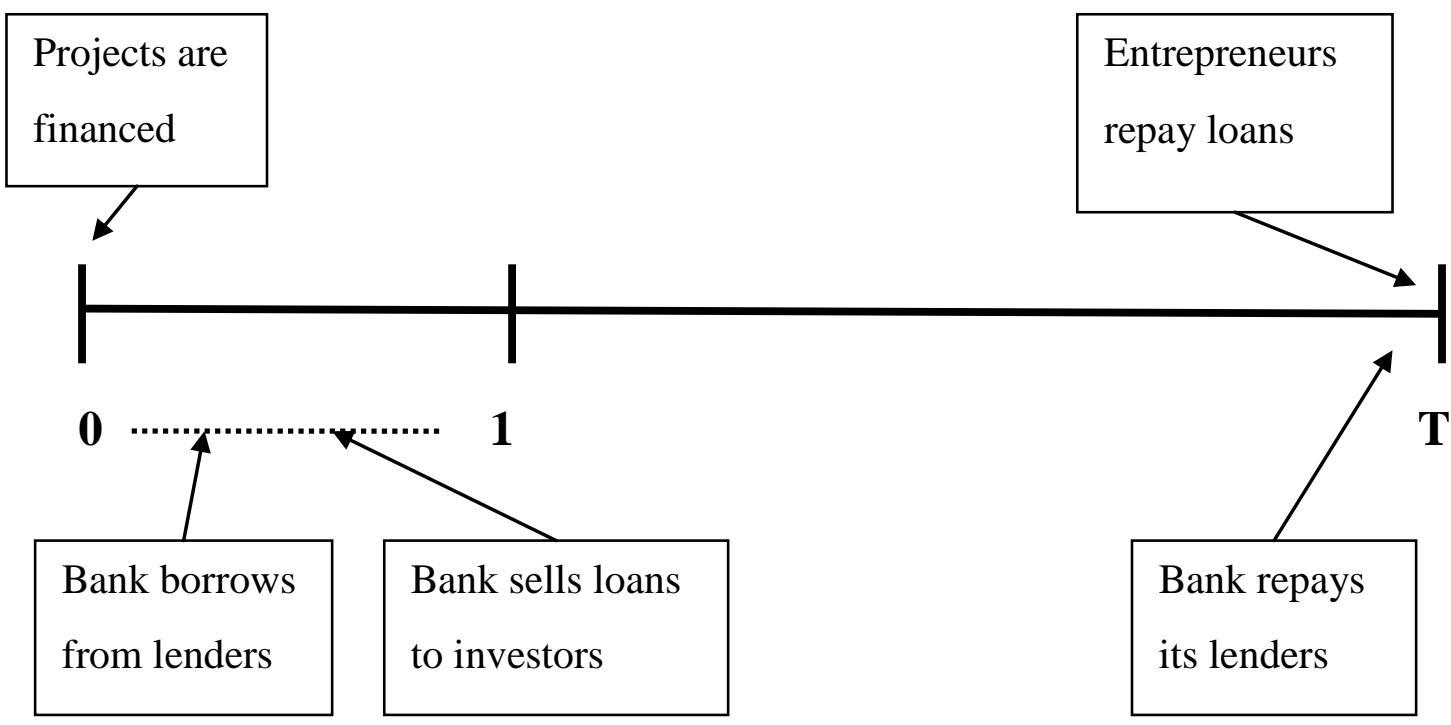


Table 1: Project Return Distribution

$\begin{array}{ccc}\text { State of the World } & \text { Outcome } & \text { Probability } \\ H & \text { All projects succeed } & \left(p_{h}\right)^{2} \\ I & \text { Only type I projects succeed } & p_{h}\left(1-p_{h}\right) \\ I I & \text { Only type II projects succeed } & p_{h}\left(1-p_{h}\right) \\ L & \text { All projects fail } & \left(1-p_{h}\right)^{2}\end{array}$

Table 2: Payoffs of Tranches

\section{State-Contingent Payoffs}

$\begin{array}{ccccc}\text { Security } & H & I & I I & L \\ W_{C}^{0} & 2 R_{L} & 2 R_{L} & 2 R_{L} & 2 R_{L} \\ W_{I}^{L} & V-R_{L} & V-R_{L} & V-R_{L} & 0 \\ W_{I}^{H} & V-w_{H}-R_{L} & 0 & 0 & 0 \\ W_{B}^{H} & w_{H} & 0 & 0 & 0\end{array}$

